\title{
Adequação de doses de nitrogênio em milho com base em indicadores de solo e de planta
}

\author{
Lisandro Rambo (1), Paulo Regis Ferreira da Silva(2), Mércio Luiz Strieder ${ }^{(2)}$, \\ Carla Andréa Delatorre ${ }^{(2)}$, Cimélio Bayer ${ }^{(3)}$ e Gilber Argenta ${ }^{(1)}$
}

\begin{abstract}
(1)Syngenta Seeds Ltda., Caixa Postal 585, CEP 38400-974 Uberlândia, MG. E-mail: lisandro.rambo@syngenta.com, gilber.argenta@syngenta.com (2)Universidade Federal do Rio Grande do Sul (UFRGS), Faculdade de Agronomia (FA), Departamento de Plantas de Lavoura, Caixa Postal 15.100, CEP 90970-100 Porto Alegre, RS. E-mail: paulo.silva@ufrgs.br, domercio@gmail.com, cadtorre@ufrgs.br(3)UFRGS, FA, Departamento de Solos. E-mail: cimelio.bayer@ufrgs.br
\end{abstract}

Resumo - $\mathrm{O}$ objetivo deste trabalho foi testar uma metodologia para determinar doses ótimas de $\mathrm{N}$ a serem aplicadas em cobertura, no estádio V6 do milho, com base em características de solo e de planta, e verificar quais os indicadores mais precisos para a predição da dose de $\mathrm{N}$ a ser aplicada. O experimento foi conduzido em Eldorado do Sul, RS, em dois anos agrícolas. Os tratamentos consistiram de cinco doses de N, aplicadas em duas épocas. Além do rendimento de grãos, determinaram-se, no estádio V6, o teor relativo de clorofila na folha, as massas de matéria seca da folha e da planta, o teor e a quantidade de $\mathrm{N}$ acumulados na folha e na planta, teores de nitrato, amônio e $\mathrm{N}$ mineral no solo. As características de planta foram mais eficientes para a predição da dose de $\mathrm{N}$ em cobertura no milho, nos dois anos agrícolas, do que as características de solo, com destaque para massa de matéria seca e $\mathrm{N}$ acumulado na planta, seguidas pelo teor relativo de clorofila na folha. É possível desenvolver ou adaptar a metodologia testada, para predição de doses ótimas de $\mathrm{N}$ em cobertura em milho, a partir de características de planta e de solo, desde que se possua uma rede de ensaios com uma curva de reposta a esse nutriente.

Termos para indexação: Zea mays, adubação de cobertura, nitrogênio na planta, nitrogênio no solo, rendimento de grãos, teor de clorofila.

\section{Adequacy of side dress nitrogen rates in corn based on soil and plant indicators}

\begin{abstract}
The objective of this work was to test one methodology to determine nitrogen (N) optimum rate to side dress at V6 corn stage, using soil and plant characteristics, and to verify which are the most precise indicators of $\mathrm{N}$ rate application. A field experiment was carried out in Eldorado do Sul, RS, Brazil, in two growing seasons. The treatments were five $\mathrm{N}$ rates applied in two timings. The following variables were measured: corn grain yield, leaf relative chlorophyll content, leaf and plant dry weight, $\mathrm{N}$ content and accumulated in the leaf, and plant and soil nitrate, ammonium and $\mathrm{N}$ mineral contents were measured at V6. From the evaluated characteristics, the most precise to predict optimum $\mathrm{N}$ rate for side dressing in corn were plant dry weight, $\mathrm{N}$ accumulated in the plant and leaf relative chlorophyll content. The results show that is possible to adapt or to develop a method to predict the optimum $\mathrm{N}$ rates for side dressing, using soil and plant characteristics, since there is a $\mathrm{N}$ response curve available from a group of experiments.
\end{abstract}

Index terms: Zea mays, topdressing, plant nitrogen, soil nitrogen, grain yield, chlorophyll content.

\section{Introdução}

No Sul do Brasil, mais especificamente nos estados do Rio Grande do Sul e Santa Catarina, o teor de matéria orgânica (MO) tem sido utilizado como principal parâmetro indicativo da disponibilidade de $\mathrm{N}$ do solo durante a estação de cultivo. O uso do teor de MO e mais recentemente da cultura anterior, como critérios indicadores da disponibilidade de $\mathrm{N}$ no solo (Amado et al., 2002), é fundamentado na premissa de que o $\mathrm{N}$ presente na MO do solo e na fitomassa das culturas antecedentes irá ser mineralizado em tempo hábil, para ser absorvido pelas plantas.

Entretanto, a mineralização do $\mathrm{N}$ orgânico do solo e das culturas é afetada por diversos fatores, com destaque para os climáticos como temperatura e umidade, e os 
de solo como acidez $(\mathrm{pH})$, textura e mineralogia (Jenkinson \& Ayanaba, 1977; Bayer, 1996). Em regiões de clima úmido, a temperatura é o fator climático que mais influencia a taxa de mineralização do $\mathrm{N}$ orgânico, que varia na ordem de duas vezes para cada variação de $10^{\circ} \mathrm{C}$ (Jenkinson \& Ayanaba, 1977). Assim, o uso de parâmetros complementares no manejo do $\mathrm{N}$ em milho pode ser benéfico.

Indicadores de solo e de planta têm sido utilizados para monitorar a disponibilidade de $\mathrm{N}$ e auxiliar na decisão sobre a dose e a época de sua aplicação, para obtenção do rendimento de grãos máximo, com maior eficiência de uso do $\mathrm{N}$ e o mínimo de impacto ambiental. Em geral, características de solo predizem com maior segurança a dose de $\mathrm{N}$ a ser aplicada, enquanto os de planta predizem a sua época de aplicação (Sunderman et al., 1997; Schröder et al., 2000).

Entre as características de solo, utilizadas como indicadores da disponibilidade de $\mathrm{N}$, destaca-se o teor de nitrato, cujo uso decorre principalmente da existência de "kits" para sua determinação, e do fato de grande parte do $\mathrm{N}$ mineral do solo estar sob a forma de nitrato (Ma \& Dwyer, 1999; Rambo et al., 2007a). Entretanto, Rambo et al. (2007a) verificaram que a avaliação do teor de amônio, além do teor de nitrato, aumenta a precisão na predição da disponibilidade de $\mathrm{N}$ no solo para o milho.

Entre as características de planta mais utilizadas como indicadoras do teor de $\mathrm{N}$ estão o teor de nitrato no colmo, a massa de matéria seca da planta, o teor e a quantidade de $\mathrm{N}$ acumulada e a intensidade da cor verde da folha (Rambo, et al., 2004). Esta última característica pode ser determinada por mensurações de reflectância (Ma et al., 2005), de absorção e de transmitância da folha (Varvel et al., 1997; Argenta et al., 2004; Rambo et al., 2007b). A clorofila, relacionada à cor verde da folha, pode ser estimada pelo uso de medidores portáteis chamados clorofilômetros, que permitem medições instantâneas do valor correspondente ao teor na folha, o qual está correlacionado com o rendimento de grãos. Estes equipamentos têm sido usados, para predizer a necessidade de adubação nitrogenada em cobertura em várias culturas, entre as quais o milho (Costa et al., 2001; Fox et al., 2001; Zebarth et al., 2002; Argenta et al., 2004; Ma et al., 2007).

$\mathrm{Na}$ literatura, dispõe-se de metodologia para determinar a dose de $\mathrm{N}$ a ser aplicada em cobertura em cereais que consiste na simulação de níveis de disponibilidade de $\mathrm{N}$ no solo no estádio inicial de desenvolvimento da cultura e, a partir da avaliação de diferentes características de solo e de planta no estádio recomendado para aplicação de $\mathrm{N}$, na identificação das características que mais se relacionam com rendimento de grãos e mais adaptadas para serem utilizadas como indicadoras do estado nutricional da planta (Scharf et al., 1993; Scharf \& Alley, 1993; Bredemeier, 1999). Essa metodologia já foi usada com êxito em trigo, cevada e aveia, tendo-se utilizado tanto características de planta (Scharf et al., 1993; Scharf \& Alley, 1993; Bredemeier, 1999) quanto de solo (Scharf \& Alley, 1993; Bredemeier, 1999). Entretanto, ela ainda não foi empregada para a cultura do milho.

Este trabalho teve como objetivo testar uma metodologia para determinar as doses ótimas de $\mathrm{N}$, a serem aplicadas em cobertura no estádio V6 do milho, com base em características de solo e de planta, e selecionar as características de solo e de planta mais precisas para serem usadas como indicadoras da dose de $\mathrm{N}$ a ser aplicada em cobertura.

\section{Material e Métodos}

A pesquisa foi baseada em experimento conduzido em campo sob alto nível de manejo, na Estação Experimental Agronômica da Universidade Federal do Rio Grande do Sul (EEA/UFRGS), em Eldorado do Sul, RS, nas estações de crescimento 2002/2003 e 2003/2004. O solo da área experimental é classificado como Argissolo Vermelho distrófico típico (Embrapa, 1999). Os resultados da análise de solo, no primeiro ano, foram: argila, $290 \mathrm{~g} \mathrm{~kg}^{-1} ; \mathrm{pH}$ em água, 5,4; índice SMP, 5,9; P (Mehlich-1), 9,4 $\mathrm{mg} \mathrm{dm}^{-3}$; $\mathrm{K}$ (Mehlich-1), $105 \mathrm{mg} \mathrm{dm}^{-3}$; MO, $25 \mathrm{~g} \mathrm{~kg}^{-1}$ e CTC, $7,6 \mathrm{cmol}_{\mathrm{c}} \mathrm{dm}^{-3}$. No segundo ano, os resultados foram: argila, $380 \mathrm{~g} \mathrm{~kg}^{-1} ; \mathrm{pH}$ em água, 5,3; índice SMP, 6,2; P (Mehlich-1), $5,6 \mathrm{mg} \mathrm{dm}^{-3} ; \mathrm{K}$ (Mehlich-1), $161 \mathrm{mg} \mathrm{dm}^{-3} ; \mathrm{MO}, 25 \mathrm{~g} \mathrm{~kg}^{-1} \mathrm{e}$ CTC, $8,1 \mathrm{cmol}_{\mathrm{c}} \mathrm{dm}^{-3}$.

Os tratamentos consistiram de cinco doses de $\mathrm{N}$ $\left(0,50,100,200\right.$ e $\left.300 \mathrm{~kg} \mathrm{ha}^{-1}\right)$, aplicados no milho em duas épocas (época 1: $20 \%$ na semeadura $+80 \%$ em cobertura no estádio V3, e época 2: $100 \%$ em cobertura no estádio V6). A fonte utilizada foi uréia, que foi manualmente aplicada nas entrelinhas do milho, sem incorporação. Porém, logo após esta prática, os experimentos foram irrigados para incorporação do $\mathrm{Ne}$ minimização das perdas por volatilização de amônia. Os tratamentos foram arranjados em delineamento de blocos ao acaso, dispostos em arranjo fatorial $5 \times 5$, com quatro repetições. A aplicação de $\mathrm{N}$, na época 1 , teve 
como objetivo simular níveis de disponibilidade de $\mathrm{N}$ no solo e, na época 2, verificar a resposta da cultura às doses de $\mathrm{N}$ aplicadas em V6, sob diferentes níveis de disponibilidade de $\mathrm{N}$.

No primeiro ano, foi semeado o híbrido simples Pioneer 32R21, de ciclo superprecoce, no dia 15 de outubro de 2002, em sistema de semeadura direta, em sucessão à aveia-preta $\left(3,4 \mathrm{Mg} \mathrm{ha}^{-1}\right.$ de rendimento de matéria seca), no espaçamento de $0,7 \mathrm{~m}$ e na densidade de 65.000 plantas ha- ${ }^{-1}$. A adubação com P e K foi realizada na linha, por ocasião da semeadura, e consistiu de $80 \mathrm{~kg} \mathrm{ha}^{-1}$ de $\mathrm{P}_{2} \mathrm{O}_{5}$ e de $60 \mathrm{~kg} \mathrm{ha}^{-1}$ de $\mathrm{K}_{2} \mathrm{O}$. No segundo ano, foi utilizado o mesmo híbrido do ano anterior, em semeadura direta realizada no dia 7 de outubro de 2003, em sucessão à aveia-preta (5,2 $\mathrm{Mg} \mathrm{ha}^{-1}$ de rendimento de matéria seca), nos mesmos espaçamento e densidade de plantas do ano anterior. A adubação com $\mathrm{Pe} \mathrm{K}$ foi realizada da mesma forma que no ano anterior, porém nas doses $105 \mathrm{~kg} \mathrm{ha}^{-1}$ de $\mathrm{P}_{2} \mathrm{O}_{5}$ e $150 \mathrm{~kg} \mathrm{ha}^{-1}$ de $\mathrm{K}_{2} \mathrm{O}$. Realizou-se o controle de plantas daninhas e de pragas, para que não interferissem no desenvolvimento da planta e no efeito de doses de $\mathrm{N}$ aplicadas sobre o rendimento de grãos. Nos dois anos, o experimento foi irrigado por aspersão, quando o potencial de água no solo era inferior a -0,04 Mpa.

Nos dois anos, determinaram-se no estádio V6: o teor relativo de clorofila na folha (TRC); a massa de matéria seca da sexta folha completamente desenvolvida e da planta; o teor e a quantidade de $\mathrm{N}$ acumulado na folha $\mathrm{e}$ na planta; e os teores de nitrato, de amônio e de $\mathrm{N}$ mineral no solo. Todas as determinações foliares foram realizadas na sexta folha, pois esta era a última folha completamente expandida (Bredemeier, 1999). O TRC, medido com clorofilômetro Minolta SPAD-502, foi determinado a partir da leitura em cinco plantas por parcela (Argenta et al., 2004). As massas de matéria seca, da sexta folha completamente desenvolvida e da planta, foram determinadas a partir de amostras de cinco folhas e de cinco plantas secas em estufa a $60^{\circ} \mathrm{C}$, até atingirem peso constante. Os teores de $\mathrm{N}$ na sexta folha completamente desenvolvida e na planta foram obtidos pela utilização das amostras coletadas para determinação de massa de matéria seca, conforme Tedesco et al. (1995). As quantidades de $\mathrm{N}$ acumuladas foram obtidas a partir do teor de $\mathrm{N}$ e da massa de matéria seca da sexta folha expandida e das plantas. O rendimento de grãos foi avaliado em área útil de $8,4 \mathrm{~m}^{2}$ por parcela, expresso em $\mathrm{Mg} \mathrm{ha}^{-1}$, à umidade de $130 \mathrm{~g} \mathrm{~kg}^{-1}$.
Os teores de nitrato e amônio no solo foram determinados em amostra composta, formada pela mistura de três subamostras de solo da camada $0-30 \mathrm{~cm}$ de profundidade, por parcela (4 linhas de $7 \mathrm{~m}$ ), coletadas nas entrelinhas do milho com trado calador. Imediatamente após a coleta, o solo foi colocado em becker com $150 \mathrm{~mL}$ de $\mathrm{KCl} 1 \mathrm{~N}$. Em seguida, foi agitado por 30 min e deixado a decantar pelo mesmo tempo. Posteriormente, foi coletado o sobrenadante e foram determinados os teores de nitrato e amônio (Tedesco et al., 1995). O teor de $\mathrm{N}$ mineral foi obtido pela soma dos teores de nitrato e de amônio no solo.

Para estabelecimento dos princípios de um sistema de predição de doses ótimas de $\mathrm{N}$, em cobertura para milho com base em características de solo e de planta, seguiu-se a metodologia utilizada por Scharf et al. (1993), Scharf \& Alley (1993) e por Bredemeier (1999) para trigo. Para tanto, inicialmente foram determinadas as doses ótimas de $\mathrm{N}$ em cobertura, para a segunda época de aplicação (estádio V6), para cada uma das doses de $\mathrm{N}$ aplicadas na primeira época (semeadura + doses aplicadas no estádio V3). Considerou-se como dose ótima aquela que resulta em maior rendimento de grãos, com a menor dose de $\mathrm{N}$ aplicada. As doses ótimas foram obtidas pela análise de regressão, quando significativa, entre as doses de $\mathrm{N}$ e o rendimento de grãos. Quando a regressão não foi significativa, a dose ótima foi obtida a partir do resultado do teste de comparação de médias (Duncan, a 5\% de probabilidade). Assim, as doses ótimas foram obtidas pelas equações de regressão para as doses de 0 e $50 \mathrm{~kg} \mathrm{ha}^{-1}$ em 2002/2003, e de 0,50 e

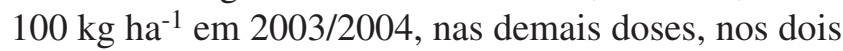
anos agrícolas, a dose ótima de $\mathrm{N}$ foi obtida pelo teste de Duncan, a 5\% de probabilidade. É importante salientar que essa metodologia só pode ser usada quando houver significância da interação entre as duas épocas de aplicação de N, para a variável rendimento de grãos. Posteriormente, as doses ótimas de $\mathrm{N}$ estimadas foram correlacionadas aos valores das características de solo e de planta, avaliadas no momento da aplicação da segunda dose de $\mathrm{N}$ em cobertura (estádio V6), para selecionar os melhores indicadores para predição da adubação nitrogenada em cobertura no milho.

\section{Resultados e Discussão}

Nos dois anos agrícolas, o rendimento de grãos de milho foi significativamente afetado pelas doses de $\mathrm{N}$ aplicadas e pela interação entre as doses aplicadas nas 
épocas 1 e 2 (Tabelas 1 e 2). O rendimento de grãos médio foi similar nos dois anos agrícolas, e foram de 10,6 $\mathrm{Mg} \mathrm{ha}^{-1} \mathrm{em}$ 2002/2003 e de 10,4 $\mathrm{Mg} \mathrm{ha}^{-1} \mathrm{em} 2003 /$ 2004.

A interação entre as doses aplicadas, nos dois estádios, possibilitou o estabelecimento do sistema de predição de doses de $\mathrm{N}$ a partir dos resultados nos dois anos agrícolas, conforme (Scharf et al., 1993; Scharf \& Alley, 1993; Bredemeier, 1999). Inicialmente, determinaram-se as doses ótimas de $\mathrm{N}$ - que resultam em maior rendimento de grãos com menor dose de $\mathrm{N}$ aplicada -, no estádio V6, para cada dose de $\mathrm{N}$ aplicada na época 1 (Tabela 2).

As doses ótimas de $\mathrm{N}$ obtidas nos dois anos foram diferentes. No primeiro ano, elas variaram de 0 a $224 \mathrm{~kg} \mathrm{ha}^{-1}$, e no segundo ano, variaram de 200 a mais de $300 \mathrm{~kg} \mathrm{ha}^{-1} \mathrm{de}$ N. Assim, no ano agrícola 2003/2004, houve maior necessidade de $\mathrm{N}$ a ser aplicado no estádio V6, para atingir o rendimento de grãos máximo, em comparação ao ano anterior. Uma das razões possíveis é a maior quantidade de palha de aveia-preta no inverno (5,2 $\mathrm{Mg} \mathrm{ha}^{-1}$ ) em 2003/2004 do que em 2002/ 2003 (3,4 Mg ha-1). A maior quantidade de palha sobre o solo pode ter resultado numa maior imobilização de $\mathrm{N}$ mineral, o que reduziu a disponibilidade deste no solo e gerou a necessidade de se aumentar a quantidade a ser aplicada no estádio V6, para se atingir o rendimento de grãos máximo. Isto pode ser confirmado ao se compararem os teores de $\mathrm{N}$ mineral no solo no estádio V6, previamente à aplicação da segunda dose de $\mathrm{N}$ em cobertura. No ano 2002/2003, o teor de N mineral no solo variou de 30 a $47 \mathrm{mg} \mathrm{kg}^{-1}$, e no segundo ano, os valores foram menores, de 16 a $33 \mathrm{mg} \mathrm{kg}^{-1}$ (Tabela 2). Além disso, o $\mathrm{N}$ acumulado na planta também foi menor no segundo ano (119 a $445 \mathrm{mg}$ de $\mathrm{N}$ por planta), em relação ao primeiro (122 a $552 \mathrm{mg}$ de $\mathrm{N}$ por planta)

Tabela 1. Análise de variância, média e coeficiente de variação (CV) do rendimento de grãos de milho, nos anos agrícolas de 2002/2003 e 2003/2004.

\begin{tabular}{lcc}
\hline Fonte de variação $^{(1)}$ & $2002 / 2003$ & $2003 / 2004$ \\
\hline Blocos & ns & $*$ \\
Dose de N - época 1 & $*$ & $*$ \\
Dose de N - época 2 & $*$ & $*$ \\
Interação entre doses de N (V3 e V6) & 10,62 & 10,39 \\
\hline Média $\left(\mathrm{Mg} \mathrm{ha}^{-1}\right)$ & 9,6 & 8,9 \\
CV (\%) & $*$ \\
(1)Época 1: 20\% do N aplicado na semeadura, e o restante em cobertura \\
em V3; época 2: $100 \%$ do N aplicado no estádio V6. ns Não-significativo. \\
*Significativo a 5\% de probabilidade, pelo teste de Duncan.
\end{tabular}

no estádio V6, o que mostra que a variação entre anos não ocorreu em função de diferenças na velocidade de absorção de N, mas sim de sua disponibilidade no solo. Estes resultados estão de acordo com os de Amado et al. (2002), que observaram que a massa de matéria seca da cultura anterior afetou significativamente a disponibilidade e a necessidade de $\mathrm{N}$ para a cultura do milho em sucessão.

A dose ótima de $\mathrm{N}$ diminuiu linearmente com o aumento nos valores das características de solo e de planta, nos dois anos agrícolas. Entre as características avaliadas em 2002/2003 (Figuras 1 e 2), os melhores indicadores para se predizerem as doses ótimas de $\mathrm{N}$ em cobertura, no estádio V6, foram as massas de matéria seca da folha e da planta, o $\mathrm{N}$ acumulado na

Tabela 2. Médias do rendimento de grãos e das características de planta de milho e de solo, e doses ótimas determinadas na época 2 (estádio V6), para cada nível de $\mathrm{N}$ aplicado na época 1 (20\% na semeadura e o restante em cobertura no estádio V3), em dois anos agrícolas.

\begin{tabular}{|c|c|c|c|c|c|}
\hline \multirow[t]{2}{*}{ Ano agrícola } & \multicolumn{5}{|c|}{ Doses de $\mathrm{N}$ aplicadas na época $1\left(\mathrm{~kg} \mathrm{ha}^{-1}\right)$} \\
\hline & 0 & 50 & 100 & 200 & 300 \\
\hline & \multicolumn{5}{|c|}{ Rendimento de grãos $\left(\mathrm{Mg} \mathrm{ha}^{-1}\right)$} \\
\hline $2002 / 2003$ & 8,6 & 10,0 & 10,5 & 11,6 & 12,3 \\
\hline \multirow[t]{2}{*}{$2003 / 2004$} & 7,7 & 9,5 & 10,7 & 11,2 & 12,8 \\
\hline & \multicolumn{5}{|c|}{ Massa de matéria seca da sexta folha (g) } \\
\hline $2002 / 2003$ & 0,49 & 0,77 & 0,91 & 1,04 & 1,03 \\
\hline \multirow[t]{2}{*}{$2003 / 2004$} & 0,76 & 0,80 & 0,77 & 0,93 & 1,05 \\
\hline & \multicolumn{5}{|c|}{ Massa de matéria seca da planta (g) } \\
\hline $2002 / 2003$ & 4,37 & 8,42 & 15,0 & 17,1 & 16,5 \\
\hline \multirow[t]{2}{*}{$2003 / 2004$} & 2,07 & 3,76 & 4,5 & 5,6 & 6,0 \\
\hline & \multicolumn{5}{|c|}{$\mathrm{N}$ acumulado por folha $(\mathrm{mg})$} \\
\hline $2002 / 2003$ & 14,2 & 27,8 & 33,6 & 35,7 & 34,0 \\
\hline \multirow[t]{2}{*}{$2003 / 2004$} & 25,9 & 27,4 & 30,3 & 31,4 & 39,9 \\
\hline & \multicolumn{5}{|c|}{$\mathrm{N}$ acumulado por planta (mg) } \\
\hline $2002 / 2003$ & 121,6 & 287,6 & 507,6 & 557,1 & 552,3 \\
\hline \multirow[t]{2}{*}{$2003 / 2004$} & 119,2 & 227,2 & 304,4 & 377,9 & 444,7 \\
\hline & \multicolumn{5}{|c|}{ Teor de N na sexta folha $(\%)$} \\
\hline $2002 / 2003$ & 2,82 & 3,63 & 3,66 & 3,41 & 3,25 \\
\hline \multirow[t]{2}{*}{$2003 / 2004$} & 3,23 & 3,42 & 3,86 & 3,32 & 3,88 \\
\hline & \multicolumn{5}{|c|}{ Teor de N na planta $(\%)$} \\
\hline $2002 / 2003$ & 2,62 & 3,42 & 3,41 & 3,24 & 3,40 \\
\hline \multirow[t]{2}{*}{$2003 / 2004$} & 5,75 & 6,10 & 6,65 & 6,92 & 7,38 \\
\hline & \multicolumn{5}{|c|}{ Leitura do clorofilômetro (SPAD) } \\
\hline $2002 / 2003$ & 40,1 & 47,9 & 51,5 & 53,8 & 52,8 \\
\hline \multirow[t]{2}{*}{$2003 / 2004$} & 36,0 & 42,4 & 48,3 & 47,4 & 49,5 \\
\hline & \multicolumn{5}{|c|}{ Teor de nitrato no solo $\left(\mathrm{mg} \mathrm{kg}^{-1}\right)$} \\
\hline $2002 / 2003$ & 13,6 & 19,1 & 17,8 & 19,4 & 19,8 \\
\hline \multirow[t]{2}{*}{$2003 / 2004$} & 8,7 & 10,7 & 14,1 & 14,1 & 16,1 \\
\hline & \multicolumn{5}{|c|}{ Teor de amônio no solo $\left(\mathrm{mg} \mathrm{kg}^{-1}\right)$} \\
\hline $2002 / 2003$ & 16,3 & 22,5 & 21,8 & 23,4 & 27,5 \\
\hline \multirow[t]{2}{*}{$2003 / 2004$} & 7,6 & 9,9 & 17,0 & 19,2 & 17,3 \\
\hline & \multicolumn{5}{|c|}{ Teor de $\mathrm{N}$ mineral no solo $\left(\mathrm{mg} \mathrm{kg}^{-1}\right)$} \\
\hline $2002 / 2003$ & 29,9 & 41,6 & 39,5 & 42,8 & 47,3 \\
\hline \multirow[t]{2}{*}{$2003 / 2004$} & 16,4 & 20,6 & 31,1 & 33,3 & 33,4 \\
\hline & \multicolumn{5}{|c|}{ Dose ótima de $\mathrm{N}$ na época $2\left(\mathrm{~kg} \mathrm{ha}^{-1}\right)$} \\
\hline $2002 / 2003$ & 224 & 221 & 100 & 0 & 0 \\
\hline $2003 / 2004$ & 318 & 271 & 231 & 200 & 200 \\
\hline
\end{tabular}



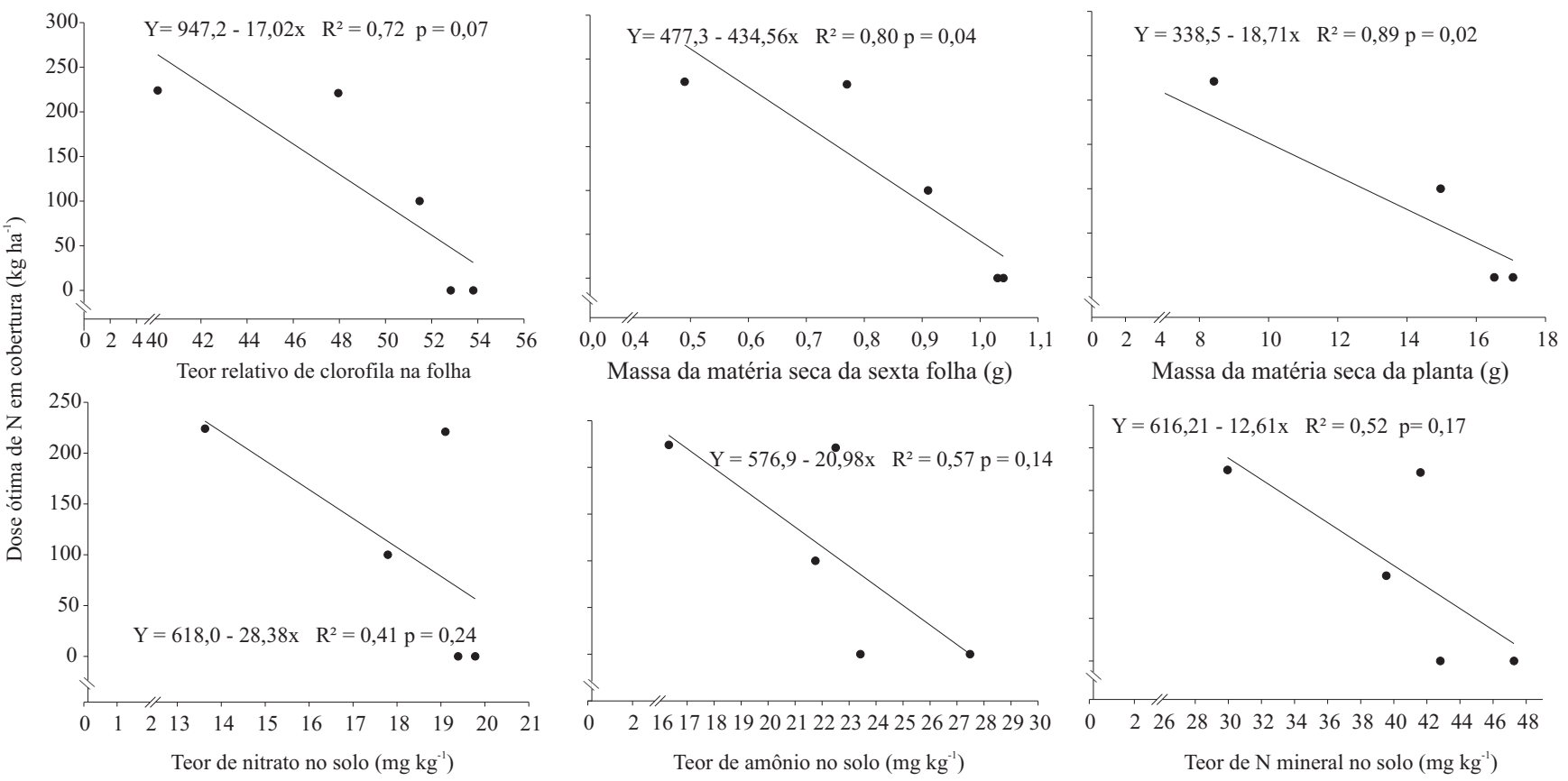

Figura 1. Doses ótimas de nitrogênio a serem aplicadas em cobertura, em função dos valores do teor relativo de clorofila na folha, massas de matéria seca da folha e da planta e teores de nitrato, amônio e nitrogênio mineral no solo, determinados na época 2 (estádio V6 do milho), no ano agrícola 2002/2003.
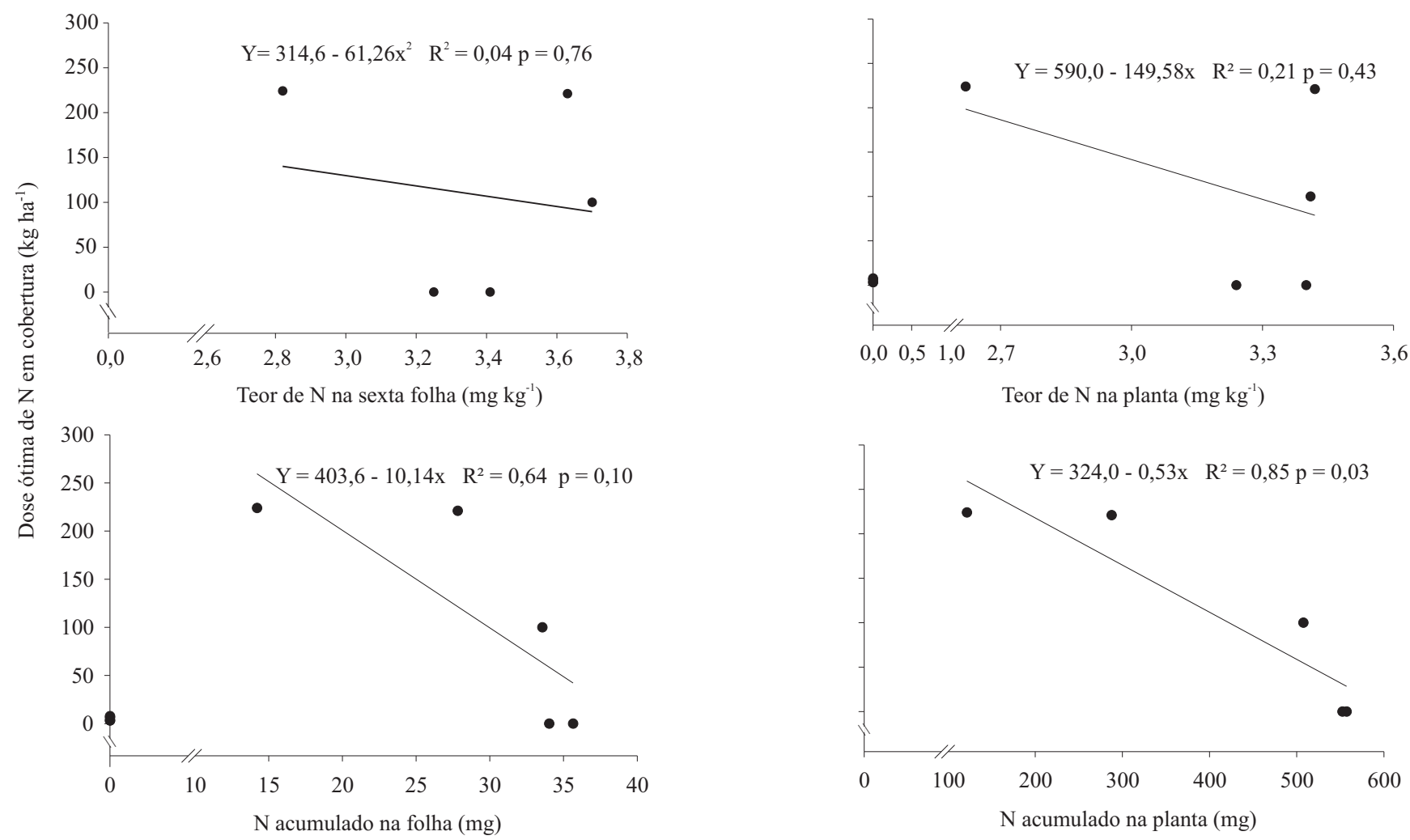

Figura 2. Doses ótimas de nitrogênio a serem aplicadas em cobertura, em função dos teores de nitrogênio na folha e na planta e das quantidades de nitrogênio acumulado na folha e na planta, determinados na época 2 (estádio V6 do milho), no ano agrícola 2002/2003. 
folha e na planta, e o teor relativo de clorofila na folha $\left(\mathrm{R}^{2}>0,60\right)$. As características de solo, teores de nitrato, amônio e $\mathrm{N}$ mineral apresentaram resultados intermediários $\left(0,25<\mathrm{R}^{2}<0,60\right)$, enquanto os teores de $\mathrm{N}$ na folha e na planta mostraram-se pouco promissores $\left(\mathrm{R}^{2}<0,25\right)$.

Em 2003/2004 (Figuras 3 e 4), as características de planta que melhor predisseram as doses ótimas de $\mathrm{N}$, a serem aplicadas em cobertura, foram massa de matéria seca da planta, $\mathrm{N}$ acumulado na planta, o teor de $\mathrm{N}$ na planta e o teor relativo de clorofila na folha $\left(\mathrm{R}^{2}>0,90\right)$, enquanto as características $\mathrm{N}$ acumulado na folha, teor de $\mathrm{N}$ na folha e massa de matéria seca da folha não apresentaram boa relação com as doses ótimas. Diferentemente de 2002/2003, as características de solo, teores de $\mathrm{N}$ mineral, de amônio e de nitrato apresentaram alta relação com as doses ótimas de $\mathrm{N}\left(\mathrm{R}^{2}>0,90\right)$.

Considerando-se os dois anos agrícolas, as características que apresentaram melhor consistência dos resultados, foram a massa de matéria seca e o $\mathrm{N}$ acumulado na planta, seguidas pelo teor relativo de clorofila na folha. Em trabalho desenvolvido por Bredemeier (1999), a massa de matéria seca também foi um dos parâmetros mais precisos. Portanto, destacaram-se quanto à consistência dos resultados as características de planta em comparação aos indicadores de solo; estes últimos apresentaram bons resultados somente no segundo ano agrícola. Estes resultados se contrapõem às observações feitas por Sunderman et al. (1997) e Schröder et al. (2000) de que, em geral, características de solo predizem com maior segurança a dose de $\mathrm{N}$ a ser aplicado em comparação com as de planta. Porém, deve-se considerar que no presente trabalho foi estudado somente o teor de $\mathrm{N}$ mineral no solo (nitrato e amônio) que, especialmente em relação ao nitrato, pode não ser tão eficiente como indicador quantitativo de N (Heckman et al., 1996).

O comportamento distinto dos indicadores de solo, principalmente do teor de nitrato, nos anos agrícolas, pode ser interpretado a partir dos seus teores no solo e do nível crítico de nitrato, acima do qual a resposta à adubação nitrogenada é improvável. Para o solo do presente trabalho, Rambo et al. (2007a) determinaram o nível crítico de $20 \mathrm{mg} \mathrm{kg}^{-1}$, valor do qual se aproximam os teores médios de nitrato do solo no primeiro ano (13,6 a $\left.19,8 \mathrm{mg} \mathrm{kg}^{-1}\right)$. A proximidade da faixa dos teores de nitrato no primeiro ano, em relação ao nível crítico, indica que, em alguns casos, o nível de nitrato encontrava-se próximo da condição de suficiência, o que explica a sua baixa relação com as doses ótimas de $\mathrm{N}$.
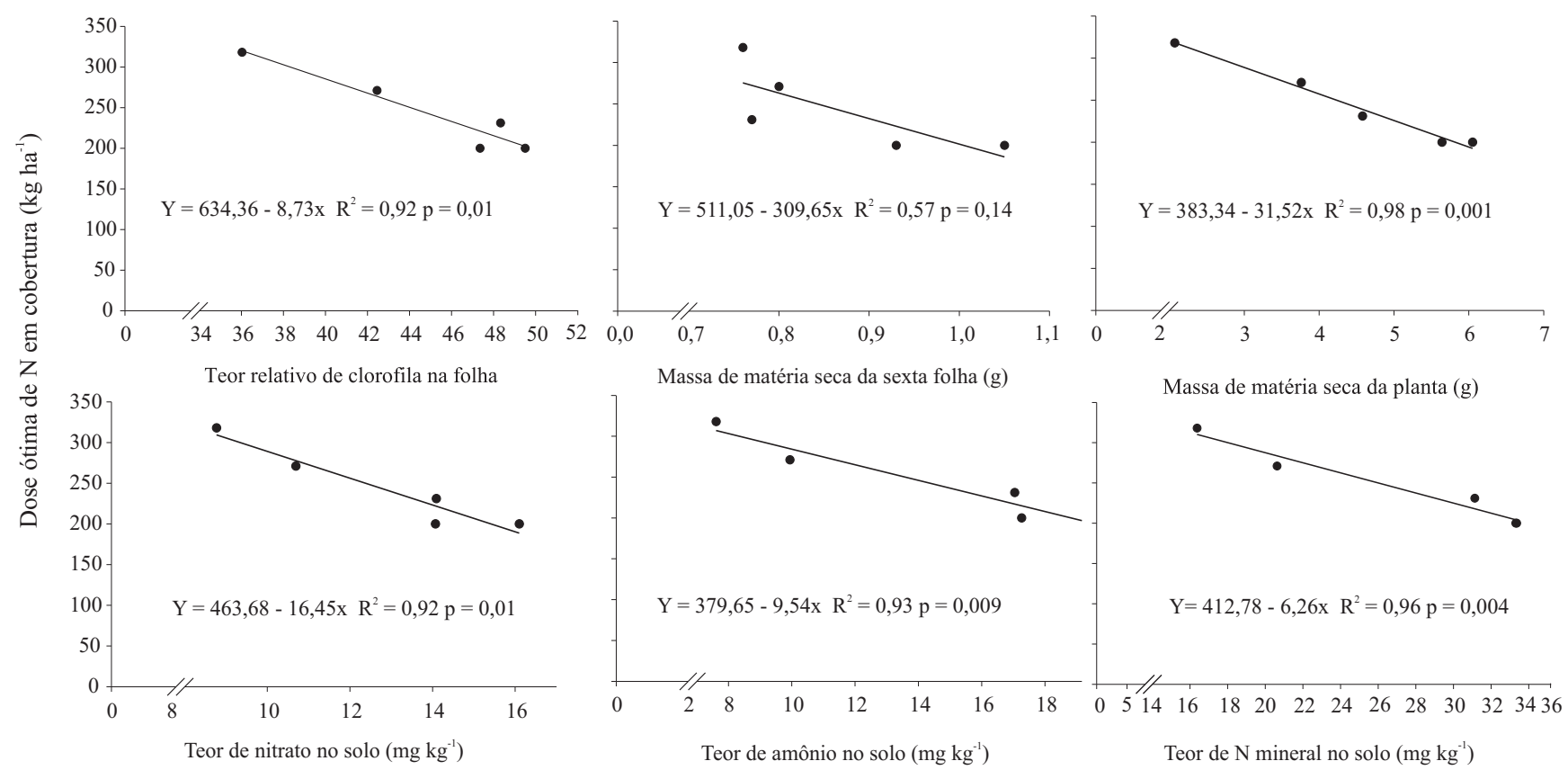

Figura 3. Doses ótimas de nitrogênio a serem aplicadas em cobertura, em função dos valores de teor relativo de clorofila na folha, massas de matéria seca da folha e da planta e teores de nitrato, amônio e nitrogênio mineral no solo, determinados na época 2 (estádio V6 do milho), no ano agrícola 2003/2004. 
Essa interpretação é reforçada, quando os dados do segundo ano agrícola são analisados. Nesse ano, a faixa dos teores médios de nitrato no solo foi mais baixa e mais ampla ( 8,8 a $\left.16,1 \mathrm{mg} \mathrm{kg}^{-1}\right)$ do que no primeiro ano, o que resultou numa boa relação deste indicador com as doses ótimas de N. O fato de os teores de nitrato no solo serem mais baixos que o nível crítico pode ter proporcionado a variabilidade necessária para haver boa relação entre esta característica e as doses ótimas de $\mathrm{N}$ aplicadas. Em relação às características teores de amônio e de $\mathrm{N}$ mineral (nitrato + amônio) no solo, pressupõe-se que a mesma explicação usada para teor de nitrato é válida para estas duas características, já que os seus valores também foram diferenciados entre os dois anos de estudo.

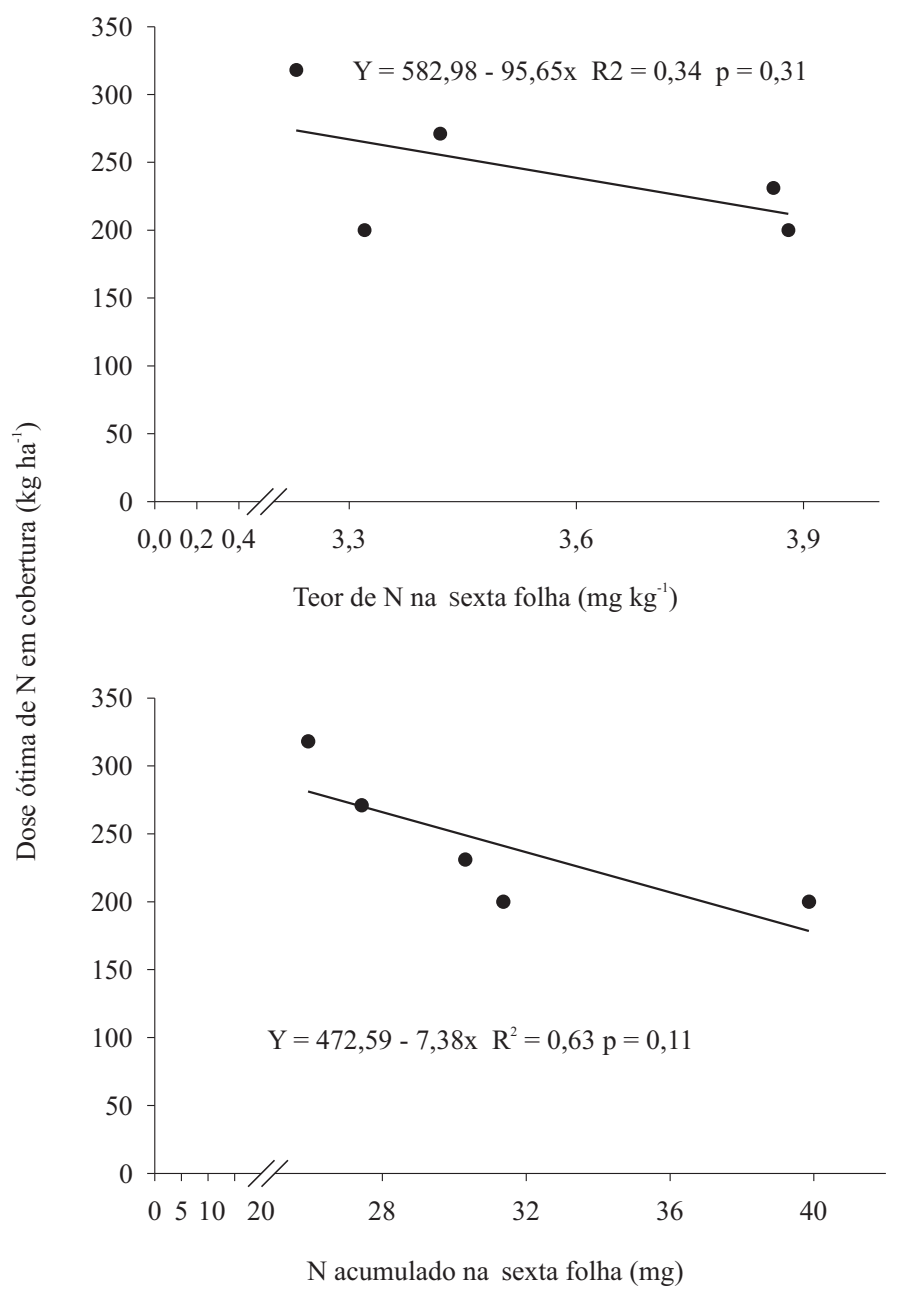

O uso do teor de nitrato no solo, como indicador da dose de $\mathrm{N}$ a ser aplicada em cobertura no milho, tem gerado resultados variáveis. Por exemplo, na Pensilvânia, Iowa e Vermont (EUA), os valores obtidos abaixo do nível crítico têm sido usados para recomendar a adubação nitrogenada (Bundy \& Meisinger, 1994; Andraski \& Bundy, 2002). Entretanto, em alguns casos, o seu uso como índice quantitativo não tem sido eficiente, principalmente em função da variabilidade na relação entre o teste e o rendimento relativo de grãos (Heckman et al., 1996). Em razão destas contradições, Bundy \& Meisinger (1994) recomendam que a adoção de indicadores de solo e de planta, para predição de doses de $\mathrm{N}$ em cobertura, deve ser avaliada em nível estadual, pois esta abordagem envolve e depende de
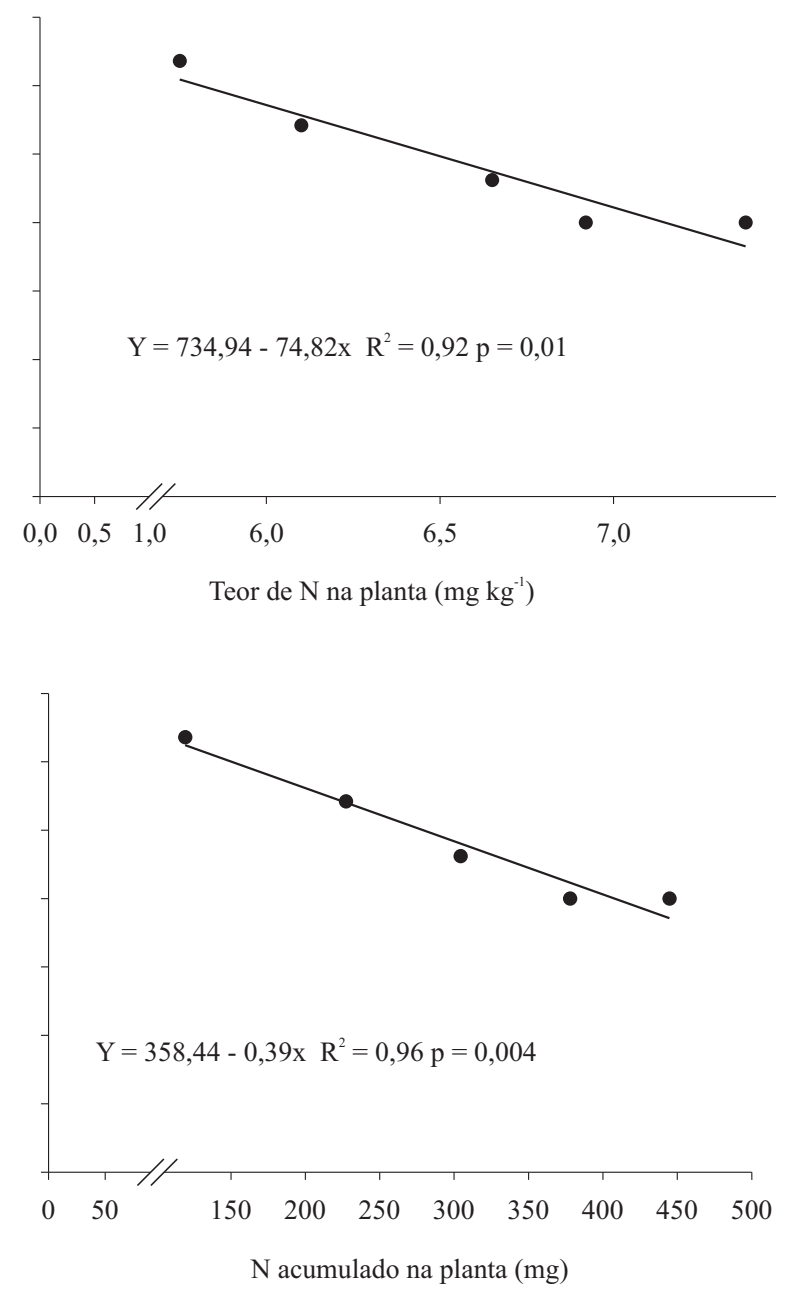

Figura 4. Doses ótimas de nitrogênio a serem aplicadas em cobertura, em função dos teores de nitrogênio na folha e na planta e das quantidades de nitrogênio acumulado na folha e na planta, determinados na época 2 (estádio V6 do milho), no ano agrícola 2003/2004. 
características específicas de solo, clima e sistema de cultivo de cada região, e dificilmente, o uso do teor de nitrato de forma isolada será eficiente para determinação da dose de $\mathrm{N}$ a ser aplicada, pois é necessária a integração com outros atributos de solo e de planta.

Dentre as características de planta avaliadas, que se mostraram consistentes nos dois anos, destacaram-se a massa de matéria seca e o $\mathrm{N}$ acumulado na planta, na predição de doses ótimas de $\mathrm{N}$ em cobertura no estádio V6, seguidas pelo teor relativo de clorofila na folha. Em relação a essas características, é necessário considerar como são afetadas pela disponibilidade de $\mathrm{N}$ e pelas demais condições ambientais. A massa de matéria seca da planta é afetada pelo teor de $\mathrm{N}$ disponível, que é constituinte de proteínas, enzimas, coenzimas, ácidos nucléicos, fitocromos e da clorofila, além de afetar as taxas de iniciação e de expansão foliar, o tamanho final e a intensidade de senescência de folhas (Schroder et al., 2000). No entanto, outros estresses abióticos como deficiência de P, estresse hídrico e limitação térmica podem limitar o crescimento e, por conseguinte, a produção de matéria seca, por isso é necessário considerar também a ocorrência destes.

$\mathrm{O}$ cálculo do teor de $\mathrm{N}$ acumulado na planta tem como maior vantagem o fato de que a produção de matéria seca é incluída no cálculo do consumo de $\mathrm{N}$ (Bredemeier, 1999). Segundo Plénet \& Lemaire (1999), a relação entre teor crítico de $\mathrm{N}$ e matéria seca acumulada indica o nível nutricional da cultura, em cada estádio de desenvolvimento, para manejo da adubação nitrogenada. Além disso, a integração desta relação em modelos de crescimento da cultura pode permitir a predição da demanda de $\mathrm{N}$ pelo milho, em função de condições ambientais. Além disso, as determinações da massa de matéria seca e do $\mathrm{N}$ acumulado na planta são trabalhosas e demoradas, o que impossibilita a tomada de decisão na mesma safra de cultivo.

O teor relativo de clorofila na folha (TRC), por apresentar baixa sensibilidade ao consumo de luxo de $\mathrm{N}$, vem sendo considerado melhor indicador do nível deste nutriente do que seu próprio teor na folha (Rambo et al., 2004). Em razão dessa vantagem, bem como pela praticidade e economia da sua determinação por clorofilômetros (Malavolta, 1997), e pela alta relação com o rendimento de grãos, a determinação do teor relativo de clorofila tem sido usada para predizer a necessidade de adubação nitrogenada em cobertura em várias culturas, especialmente em trigo (Bredemeier, 1999; Singh et al., 2002), arroz (Stalin et al., 2000; Singh et al., 2002) e milho (Varvel et al., 1997; Costa et al., 2001; Fox et al., 2001; Zebarth et al., 2002; Argenta et al., 2004).
No entanto, na literatura, não foram encontrados trabalhos que tenham utilizado o TRC para predizer a dose de $\mathrm{N}$ a ser aplicada, quando detectada sua deficiência pelo clorofilômetro. Nesse sentido, apesar de os resultados do TRC obtidos no presente estudo terem sido positivos, eles não foram suficientemente consistentes, para recomendação do seu uso como indicador da dose de $\mathrm{N}$ a ser aplicada em milho; há, portanto, a necessidade de condução de mais trabalhos em outros ambientes e situações de manejo.

Os resultados evidenciaram que a metodologia testada para determinação de doses ótimas de N, a serem aplicadas em cobertura a partir de características de planta e de solo, pode ser utilizada para a cultura do milho, mas apresenta várias limitações. Um dos maiores entraves ao seu uso está relacionado à dificuldade de execução e à necessidade de condução de experimentos de grande dimensão, já que a metodologia original pressupõe a aplicação de vários níveis de $\mathrm{N}$ em duas épocas, de modo que se disponha do máximo de pontos possíveis, para se estimarem as doses ótimas, com a finalidade de maior precisão da metodologia. No entanto, esta limitação pode ser superada, com a utilização de dados de uma rede de ensaios que disponibilize uma curva de resposta a $\mathrm{N}$ com poucos pontos em cada local, para se escolher e calibrar o parâmetro de planta e solo escolhido. Esta rede de ensaios substituiria a necessidade de aplicação prévia de $\mathrm{N}$ para construção de gradientes de resposta, condição que torna o experimento demasiadamente grande. Além disso, caso esta metodologia seja utilizada para a recomendação de adubação nitrogenada para a cultura do milho, sugerese que sejam usadas doses ótimas econômicas, para se escolher e calibrar os parâmetros testados.

A inclusão de outros parâmetros de planta e de solo, além do teor de matéria orgânica, numa rede de ensaios para predição de doses de $\mathrm{N}$ para a cultura do milho, pode aumentar a precisão, ao incrementar a eficiência de uso do N, e gerar menor custo de produção e maior proteção do ambiente.

\section{Conclusões}

1. As características mais precisas para predição das doses ótimas de $\mathrm{N}$, a serem aplicadas em cobertura em milho, são a massa de matéria seca e o $\mathrm{N}$ acumulado na planta, seguidas do teor relativo de clorofila na folha que, em razão de sua praticidade e facilidade de obtenção, apresenta maior potencial de uso. 
2. É possível adequar a metodologia testada para predição de doses ótimas de $\mathrm{N}$ em cobertura em milho, a partir de características de planta e de solo.

\section{Referências}

AMADO, T.J.C.; MIELNICZUK, J.; AITA, C. Recomendação de adubação nitrogenada para o milho no RS e SC adaptada ao uso de culturas de cobertura do solo, sob sistema de plantio direto. Revista Brasileira de Ciência do Solo, v.26, p.241-248, 2002.

ANDRASKI, T.W.; BUNDY, L.G. Using the pre-sidedress soil nitrate test and organic nitrogen crediting to improve corn nitrogen recommendations. Agronomy Journal, v.94, p.1411-1418, 2002.

ARGENTA, G.; SILVA, P.R.F. da; SANGOI, L. Leaf relative chlorophyll content as an indicator parameter to predict nitrogen fertilization in maize. Ciência Rural, v.34, p.1379-1387, 2004.

BAYER, C. Dinâmica da matéria orgânica em sistemas de manejo de solos. 1996. 240p. Tese (Doutorado) - Universidade Federal do Rio Grande do Sul, Porto Alegre.

BREDEMEIER, C. Predição da necessidade de nitrogênio em cobertura em trigo e aveia. 1999. 101p. Dissertação (Mestrado) Universidade Federal do Rio Grande do Sul, Porto Alegre.

BUNDY, L.G.; MEISINGER, J.J. Nitrogen availability indices. In: WEAVER, R.W.; ANGLE, S.; BOTTOMLEY, P.; BEZDIECEK, D.; TABATABAI, A.; WOLLUM, A.; MICKELSON, S.H.; BIGHAM, J.M. Methods of soil analysis: part 2: microbiological and biochemical properties. Madison: SSSA, 1994. p.951-984.

COSTA, C.; DWYER, L.M.; DUTILLEUL, P.; HAMILTON, R.I.; STEWART, D.W.; MA, B.L.; SMITH, D.L. Inter-relationships of applied nitrogen, SPAD, and yield of leafy and non-leafy maize genotypes. Journal of Plant Nutrition, v.24, p.1173-1194, 2001. EMBRAPA. Sistema brasileiro de classificação de solos. Brasília: Embrapa-SPI; Rio de Janeiro: Embrapa-CNPS, 1999. 412p.

FOX, R.H.; PIEKIELEC, W.P.; MACNEAL, K.E. Comparison of late-season diagnostic tests for predicting nitrogen status of corn. Agronomy Journal, v.93, p.590-597, 2001.

HECKMAN, J.R.; GOVINDASAMY, R.; PROSTAK, D.J.; CHAMBERLAIN, E.A.; HLUBIK, W.T.; MICKEL, R.C.; PROSTKO, E.P. Corn response to side-dress nitrogen in relation to soil nitrate concentration. Communications in Soil Science and Plant Analysis, v.27, p.575-583, 1996.

JENKINSON, D.S.; AYANABA, A. Decomposition of carbon-14 labeled plant material under tropical conditions. Soil Science Society of America Journal, v.41, p.912-915, 1977.

MA, B.L.; DWYER, L.M. Within plot variability in available soil mineral nitrogen in relation to leaf greenness and yield. Communications in Soil Science and Plant Analysis, v.30, p.1919-1928, 1999.

MA, B.L.; SUBEDI, K.D.; COSTA, C. Comparison of crop-based indicators with soil nitrate test for corn nitrogen requeriment. Agronomy Journal, v.97, p.462-471, 2005.

MA, B.L.; SUBEDI, K.D.; ZHANG, T.Q. Pre-sidedress nitrate test and other crop-based indicators for fresh market and processing sweet corn. Agronomy Journal, v.99, p.174-183, 2007.
MALAVOlTA, E.; VITTI, G.C.; OLIVEIRA, S.A. Avaliação do estado nutricional das plantas: princípios e aplicações. 2.ed. Piracicaba: Potafos, 1997. 319p.

PLÉNET, D.; LEMAIRE, G. Relationships between dynamics of nitrogen uptake and dry matter accumulation in maize crops: determination of critical N concentration. Plant and Soil, v.216, p.65-82, 1999.

RAMBO, L.; SILVA, P.R.F.; ARGENTA, G.; SANGOI, L. Parâmetros de planta para aprimorar o manejo da adubação nitrogenada de cobertura em milho. Ciência Rural, v.34, p.1637-1645, 2004.

RAMBO, L.; SILVA, P.R.F.; BAYER, C.; ARGENTA, G.; STRIEDER, M.L.; SILVA, A.A. Teor de nitrato como indicador complementar da disponibilidade de nitrogênio no solo para o milho. Revista Brasileira de Ciência do Solo, v.31, p.731-738, 2007a.

RAMBO, L.; SILVA, P.R.F.; STRIEDER, M.L.; SANGOI, L.; BAYER, C.; ARGENTA, G. Monitoramento do nitrogênio na planta e no solo para predição da adubação nitrogenada em milho. Pesquisa Agropecuária Brasileira, v.42, p.407-417, $2007 \mathrm{~b}$.

SCHRÖDER, J.J.; NEETESON, J.J.; OENEMA, O.; STRUIK, P.C. Does the crop or the soil indicate how to save nitrogen in maize production? Reviewing the state of art. Field Crops Research, v.66, p.151-164, 2000.

SCHARF, P.C.; ALLEY, M.M. Spring nitrogen on winter wheat: II. A flexible multicomponent rate recommendation system. Agronomy Journal, v.85, p.1186-1192, 1993.

SCHARF, P.C.; ALLEY, M.M.; LEI, Y.Z. Spring nitrogen on winter wheat: I. Farmer-field validation of tissue test-based rate recommendations. Agronomy Journal, v.85, p.1181-1186, 1993.

SINGH, B.; SINGH, Y.; LADHA, J.K.; BRONSON, K.F.; BALASUBRAMANIAN, V.; SINGH, J.; KHIND, C.S. Chlorophyll meter and leaf color chart based nitrogen management for rice and wheat in Northwestern India. Agronomy Journal, v.94, p.821-829, 2002.

STALIN, P.; THIYAGARAJAN, T.M.; RAMANATHAN, S.; SUBRAMANIAN, M. Comparing management techniques to optimize fertilizer $\mathrm{N}$ application in rice in the Cauvery Delta of Tamil Nadu, India. International Rice Research Institute, v.25, p.25-26, 2000.

SUNDERMAN, H.D.; PONTUS, J.S.; LAWLESS, J.R. Variability in leaf chlorophyll concentration among full-fertilized corn hybrids. Communications in Soil Science and Plant Analysis, v.28, p.1793-1803, 1997.

TEDESCO, M.J.; GIANELLO, C.; BISSANI, C.A. Análise de solos, plantas e outros materiais. 2.ed. Porto Alegre: UFRGS, 1995. 174p. (Boletim Técnico de Solos, 5).

VARVEL, G.E.; SCHEPERS, J.S.; FRANCIS, D.D. Ability for inseason correction of nitrogen deficiency in corn using chlorophyll meter. Soil Science Society of America Journal, v.61, p.12331239, 1997.

ZEBARTH, B.J.; YOUNIE, M.; PAUL, J.W.; BITTMAN, S. Evaluation of leaf chlorophyll index for making fertilizer nitrogen recommendations for silage corn in a high fertility environment. Communications in Soil Science and Plant Analysis, v.33, p.665684, 2002. 